\title{
High Dose Octreotide for the Treatment of Chylothorax in Three Neonates
}

Makoto Saito*, Tomohiro Kamoda, Daigo Kajikawa, Yayoi Miyazono, Yu Kanai, Satoshi Fujiyama, Ryoko Suzuki, Miho Takahashi- Igari, Yasuhisa Urita and Ryo Sumazaki

Department of Pediatrics and Pediatric Surgery, University of Tsukuba Hospital, Ibaraki, Japan

*Corresponding author: Makoto Saito, Department of Pediatrics, University of Tsukuba Hospital, 1-1-1 Tennoudai, Tsukuba 305-8575, Ibaraki, Japan, Tel: +81-29-853-5635, Fax: +81-29-853-8819, E-mail: msaito@ md.tsukuba.ac.jp

Rec date: April 05, 2016; Acc date: May 02, 2016; Pub date: May 07, 2016

Copyright: (c) 2016 Saito M, et al. This is an open-access article distributed under the terms of the Creative Commons Attribution License, which permits unrestricted use, distribution, and reproduction in any medium, provided the original author and source are credited.

\begin{abstract}
Chylothorax is an abnormal condition of lymphatic fluid collection in the pleural space, and the somatostatin analog octreotide is thought to have a beneficial effect on chylothorax. However, the octreotide dosage and administration route for chylothorax have been inconsistent to date. We report three neonatal cases of persistent chylothorax successfully treated with high-dose octreotide infusion therapy $(20 \mu \mathrm{g} / \mathrm{kg} / \mathrm{h})$. Case 1 was congenital chylothorax, Case 2 was secondary chylothorax after an operation for congenital diaphragmatic hernia, and Case 3 was chylothorax after a cardiac operation. In all cases, the chylothorax was not decreased by a low-dose octreotide infusion, but after a high-dose octreotide infusion, the chylothorax decreased and eventually vanished, with no side effects.
\end{abstract}

Conclusion: We suggest that the dose of octreotide in neonatal chylothorax can be safely increased to a maximum of $20 \mu \mathrm{g} / \mathrm{kg} / \mathrm{h}$.

Keywords: Chylothorax; Octreotide; Somatostatin

\section{Abbreviations:} Unit

MCT: Medium-chain-triglyceride; NICU: Neonatal Intensive Care

\section{Introduction}

Chylothorax is an abnormal condition of lymphatic fluid collection in the pleural space and is caused by a variety of etiologies such as congenital abnormalities and postoperative complications. The diagnosis of chylothorax is usually established by a fluid analysis, including a triglyceride content $\geq 1.1 \mathrm{mmol} / \mathrm{L}$ and a total cell count of $\geq 1000$ cells $/ \mathrm{mm}^{3}$ or $\geq 80 \%$ lymphocytes [1].

Many authors have recommended a number of therapeutic interventions for chylothorax, but no uniform guidelines exist. Octreotide, a somatostatin analog, is thought to have a beneficial effect on chylothorax through the vascular somatostatin receptor, leading to reduction in chyle production. However, the optimal octreotide dosage and administration route for chylothorax have been inconsistent to date $[2,3]$. We report three neonatal cases of persistent chylothorax successfully treated with a high dose of octreotide.

\section{Case Reports}

\section{Case 1}

A female neonate was born at term weighing $2,874 \mathrm{~g}$ by an emergency caesarean section due to non-reassuring fetal status. The mother was 36 yrs old. Since a routine ultrasound at 33-wk gestation showed fetal hydrops and chylothorax, fetal thoracocentesis was performed in our hospital at $33 \mathrm{wks}$, but it was not effective.At birth, the neonate had severe respiratory distress and required immediate tracheal intubation and mechanical ventilation, and was admitted to our neonatal intensive care unit (NICU). The Apgar scores were 2 and 4 at 1 and $5 \mathrm{~min}$, respectively, and no pathological findings were found in the placenta or umbilical cord. The patient had severe bilateral pleural effusion on the first chest radiograph and required chest drainage (Figure 1).

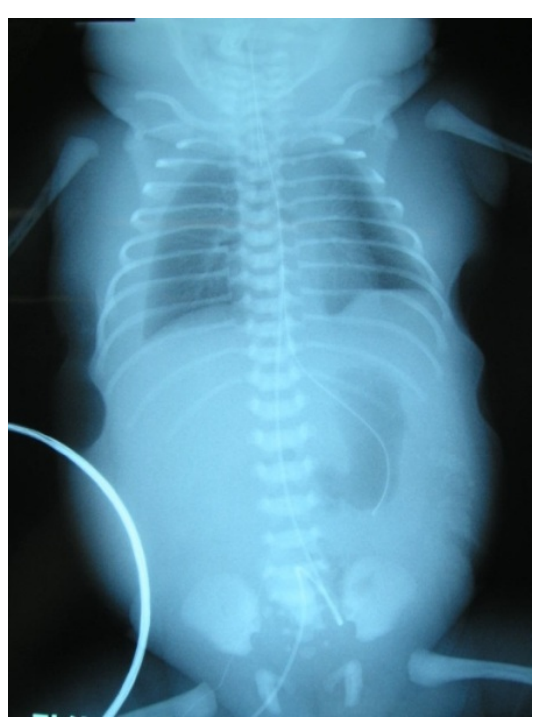

Figure 1: X-ray picture showing the presence of pleural effusion, ascites, and subcutaneous edema in case 1 .

The diagnosis of chylothorax was confirmed by the predominance of lymphocytes (cell count 1,832 cells $/ \mu \mathrm{L}$, lymphocytes 1,738 cells $/ \mu \mathrm{L}$ ) in the pleural fluid from the chest drainage. Nothing per os and total 
parenteral nutrition were started as the initial management of the chylothorax, but the pleural effusion increased. On day 9 , the pleural effusion increased to $>500 \mathrm{~mL} /$ day, and octreotide therapy was commenced at $3 \mu \mathrm{g} / \mathrm{kg} / \mathrm{h}$ after obtaining informed consent. The dose of octreotide was increased to an approx. double quantity every 3 days with no side effects. The pleural effusion was not decreased by 15 $\mu \mathrm{g} / \mathrm{kg} / \mathrm{h}$, but on day 18 , the pleural effusion significantly diminished at the dose of $20 \mu \mathrm{g} / \mathrm{kg} / \mathrm{h}$. On day 30, the pleural effusion subsided completely and on day 54, octreotide was stopped. On day 32 , medium-chain-triglyceride (MCT)-enriched formula was started and on day 94, normal formula feeding started, and the chylothorax did not recur (Figure 2a). On day 102, the patient was discharged.

\section{Case 2}

The mother was 35 yrs old, gravida 1, para 1. Fetal ultrasonography showed malposition of the heart at 23 wks, and congenital diaphragmatic hernia at 24 wks. The mother had gestational diabetes, which was treated with insulin since 24 -wk gestation. The $2,658 \mathrm{~g}$ male neonate was born by vaginal delivery at 37 wks and 1 day of gestation. He had severe respiratory distress and required immediate mechanical ventilation at birth. The Apgar scores were 2 and 3 at 1 and $5 \mathrm{~min}$, respectively, and no pathological findings were found in the placenta or umbilical cord. The first chest radiograph revealed severe left congenital diaphragmatic hernia without pleural effusion. He was initially placed on high-frequency oscillation under sedation and was treated with inotropic medicine (dopamine and dobutamine) and a vasodilator. On day 13, the diaphragmatic defect was repaired by patch closure. After the surgery, the pleural effusion was appeared in the left thorax, and on day 25 , he was diagnosed with chylothorax by the predominance of lymphocytes (cell count 1,564 cells $/ \mu \mathrm{L}$, lymphocytes $1,460$ cells $/ \mu \mathrm{L})$ in the pleural fluid. On day 46 , since the pleural effusion had increased to $>120 \mathrm{~mL} /$ day, octreotide therapy was commenced at $1 \mu \mathrm{g} / \mathrm{kg} / \mathrm{h}$ after obtaining informed consent. The dose of octreotide was increased by an approx. double quantity every 1 to 3 days with no side effects. The pleural effusion was not decreased by 14 $\mu \mathrm{g} / \mathrm{kg} / \mathrm{h}$ of octreotide, but on day 57 , the pleural effusion was significantly decreased at the dose of $20 \mu \mathrm{g} / \mathrm{kg} / \mathrm{h}$. The effusion subsided on day 59 and never re-accumulated after the cessation of octreotide therapy (Figure 2b). MCT-enriched milk started on day 69 and normal formula on day 104. On day 253, he was discharged without complications of octreotide or a recurrence of chylothorax.

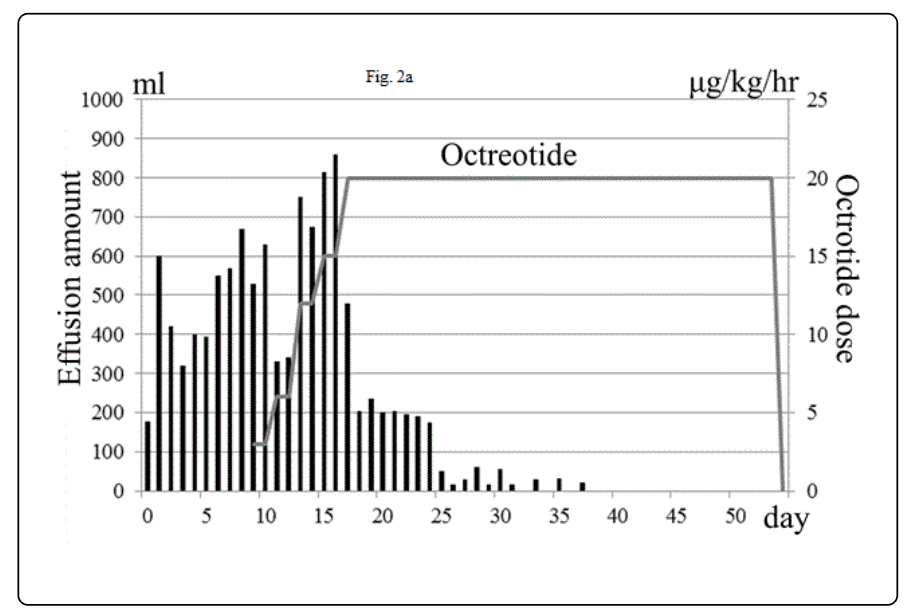

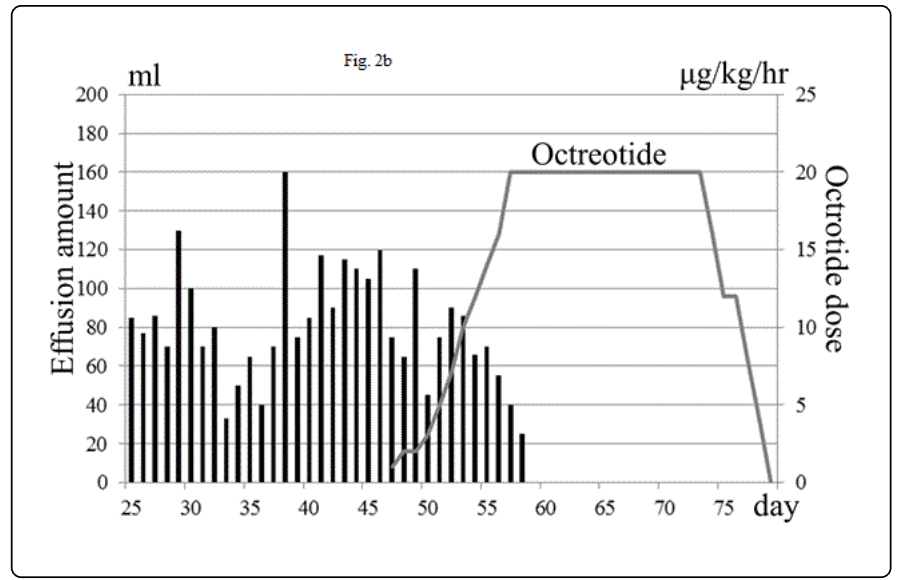

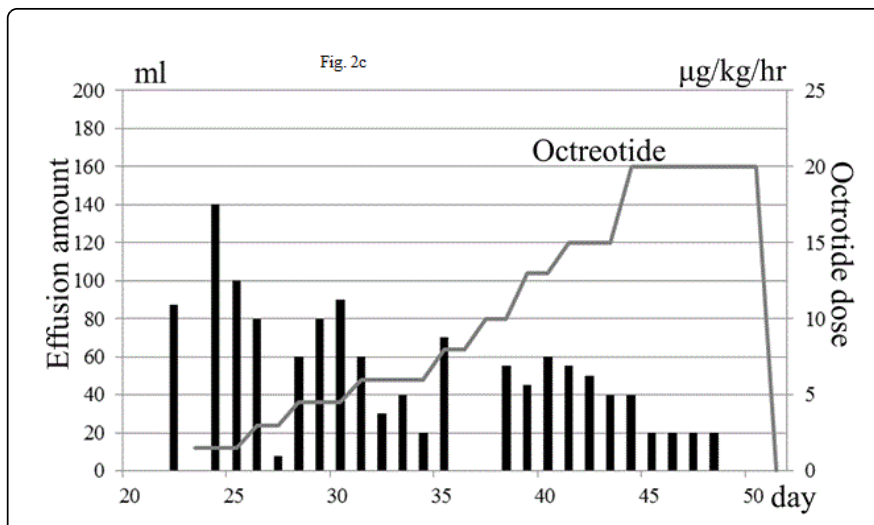

Figure 2: Graph showing the amount of pleural effusion (bar chart) and octreotide dose in the patients (2a, case $1 ; 2 \mathrm{~b}$, case $2 ; 2 \mathrm{c}$, case 3 ).

\section{Case 3}

The patient was a newborn who was antenatally diagnosed as having cardiac malposition and single ventricle and pulmonary artery stenosis by fetal ultrasonography. Her mother was 35 yrs old and had gestational diabetes. The $3,185 \mathrm{~g}$ female neonate was delivered by vaginal mode at 37 wks and 1day of gestation. After admission to our NICU she was diagnosed with single ventricle and coarctation of the aorta and complete transposition of the great vessels. The first chest radiograph revealed no plerural effusion. On day 10, the pulmonary artery was banded and the aortic arch was repaired. After the surgery she developed chylothorax with 7,600 cells/ $\mu \mathrm{L}$ and lymphocytes at 17,413 cells $/ \mu \mathrm{L}$. On day 23 , octreotide therapy was commenced at 1 $\mu \mathrm{g} / \mathrm{kg} / \mathrm{h}$ after obtaining informed consent, and the infusion quantity of octreotide was increased every 2 to 4 days. On day 45, the dosage of octreotide was increased to $20 \mu \mathrm{g} / \mathrm{kg} / \mathrm{h}$, and the chylothorax resolved by day 49 . Finally, octreotide was stopped on day 52 (Figure 2c). MCTenriched formula started on day 25 , and regular milk formula started on day 60. She was discharged on day 96. No adverse effects of octreotide therapy were observed.

\section{Discussion}

Chylothorax in neonates is a relatively rare disease. The etiology of chylothorax includes congenital anomalies, postoperative complication, thrombosis of the subclavian vein, lymphangiectasis, 
Citation: Saito M, Kamoda T, Kajikawa D, Miyazono Y, Kanai Y, et al. (2016) High Dose Octreotide for the Treatment of Chylothorax in Three Neonates. J Neonatal Biol 5: 218. doi:10.4172/2167-0897.1000218

Page 3 of 3

injuries of the thoracic duct, and tumors. Neonates with chylothorax may present with massive lymph loss inducing critical loss of fluid, lymphocytes, protein, coagulation factors, and antibodies [4]. There is no standard regime for the treatment of neonatal chylothorax, but many medical therapies have been reported such as total parenteral nutrition, medium-chain triglycerides, pleurodesis, and surgical interventions such as the ligation of the thoracic duct [1-8].

As one of the current therapeutic options, octreotide has been successfully used for the treatment of pediatric patients with chylothorax [5]. Octreotide is an analog of somatostatin, and it is the only pharmacologic agent that has been used successfully to manage chylothorax [8]. The safety and efficacy of octreotide in the treatment of chylothorax in neonates has not been evaluated properly [6], but various octreotide doses were reported in clinical case studies [4]. Lim et al. reported that the dosage of octreotide could be increased to 15 $\mu \mathrm{g} / \mathrm{kg} / \mathrm{h}$ in one case without any serious side effects [7]. Stajich et al. suggested in their review that octreotide infusion rates could be increased to a maximum dose of $24 \mu \mathrm{g} / \mathrm{kg} / \mathrm{h}$. However, no patients treated with such a high dose of octreotide have been previously reported [4], to our knowledge. According to those previous reports, we gradually increased the octreotide dose to $20 \mu \mathrm{g} / \mathrm{kg} / \mathrm{h}$ and thus found that octreotide could be used successfully at a high dose in three patients.

Major side effects of octreotide such as nausea, loose stools, hyperglycemia, cutaneous flushing, transient abdominal distention, liver dysfunction, transient hypothyroidism, necrotizing enterocolitis, and ileus have been reported [5]. Though no such side effects were found in our patients, high-dose octreotide therapy should be performed carefully.

In conclusion, we reported the cases of three neonates with chylothorax who were treated with high-dose octreotide without any side effects. We suggest that the dose of octreotide in neonatal chylothorax can be increased to a maximum of $20 \mu \mathrm{g} / \mathrm{kg} / \mathrm{h}$.

\section{References}

1. Battin MR, Yan J, Aftimos S, Roberts A (2000) Congenital chylothorax in siblings. BJOG 107: 1516-1518.

2. Cardoso D, Tuna M, Abrantes M, dos Santos HG, Da Silva LJ (2001) Congenital chylothorax associated with trisomy X. Eur J Pediatr 160: 743.

3. Das A, Shah PS (2010) Octreotide for the treatment of chylothorax in neonates. Cochrane Database Syst Rev : CD006388.

4. Stajich GV, Ashworth L (2006) Octreotide. Neonatal Netw 25: 365-369.

5. Roehr CC, Jung A, Proquitté H, Blankenstein O, Hammer H, et al. (2006) Somatostatin or octreotide as treatment options for chylothorax in young children: a systematic review. Intensive Care Med 32: 650-657.

6. Helin RD, Angeles ST, Bhat R (2006) Octreotide therapy for chylothorax in infants and children: A brief review. Pediatr Crit Care Med 7: 576-579.

7. Lim KA, Kim SH, Huh J, Kang IS, Lee HJ, et al. (2005) Somatostatin for postoperative chylothorax after surgery for children with congenital heart disease. J Korean Med Sci 20: 947-951.

8. Buettiker V, Hug MI, Burger R, Baenziger O (2001) Somatostatin: a new therapeutic option for the treatment of chylothorax. Intensive Care Med 27: 1083-1086. 